\title{
Prolonged duration of anesthesia in a patient with multiple sclerosis following paravertebral block
}

\section{[Prolongation de l'anesthésie après un bloc paravertébral chez une patiente}

\author{
atteinte de sclérose en plaques]
}

Brendan T. Finucane MBBCH FRCPC, Ockert C. Terblanche MD

Purpose: To explore the possibility that the prolonged duration of anesthesia following paravertebral block was related to the presence of multiple sclerosis in a patient undergoing elective inguinal hernia repair.

Clinical features: A healthy 33-yr-old female presented for elective inguinal hernia repair. The procedure was performed under general anesthesia and a paravertebral block was performed at the end of the procedure for postoperative pain relief, whilst the patient was still anesthetized. Upon recovering from general anesthesia it was noted that the patient had a flaccid paralysis of both lower extremities. She was also very nauseated and required antiemetics and vasopressors for hypotension. A differential diagnosis of subarachnoid, subdural or epidural spread was considered. The presence of an epidural hematoma was also considered. The block regressed very slowly with full return of function in $12.5 \mathrm{hr}$. The duration of action of the block was far longer than one would expect following spinal, epidural or subdural spread of a local anesthetic. Urinary catheterization was performed electively to prevent urinary retention. The patient was discharged home late that evening. Prior to discharge she volunteered that she was being investigated for multiple sclerosis. One month later the diagnosis of multiple sclerosis was confirmed.

Conclusion: In conclusion the extended duration of central neural blockade following paravertebral block, may have been related to an abnormal uptake of local anesthetics into the spinal cord in the presence of demyelination.

Objectif : Vérifier l'hypothèse voulant que la durée prolongée de l'anesthésie suivant un bloc paravertébral soit reliée à la présence de sclérose en plaques chez une patiente qui a subi la cure d'une hernie inguinale réglée.

Éléments cliniques : La cure d'une hernie inguinale réglée a été réalisée chez une femme de 33 ans. L'opération, sous anesthésie générale, a été suivie d'un bloc paravertébral pour l'analgésie postopératoire alors que la patiente était toujours anesthésiée. Au réveil de l'anesthésie générale, on a noté une paralysie flasque aux deux membres inférieurs. La patiente était aussi nauséeuse et a reçu des antiémétiques et des vasopresseurs pour l'hypotension. Un diagnostic différentiel d'extension sous-arachnoïdienne, sous-durale ou péridurale du bloc a été envisagé. On a considéré aussi à la présence d'un hématome péridural. Le bloc a régressé très lentement et la récupération fonctionnelle complète a exigé 12,5 h. La durée d'action du bloc a été beaucoup plus longue qu'on pouvait s'y attendre à la suite de la diffusion rachidienne, péridurale ou sous-durale d'un anesthésique local. Un cathétérisme urinaire a été réalisé pour empêcher la rétention urinaire. Avant son départ, tard le soir, la patiente a souligné qu'elle devait subir des examens pour la sclérose en plaques ; le diagnostic a été confirmé un mois plus tard.

Conclusion : La durée prolongée du bloc neural central qui suit un bloc paravertébral peut être reliée à un captage anormal d'anesthésique local dans la moelle épinière en présence de démyélinisation.

W E report a case of prolonged duration of anesthesia following a paravertebral block in a patient presenting for inguinal hernia repair. The patient was subsequently diagnosed with multiple sclerosis (MS). The purpose of this report is to explore the possibility that the prolonged duration of anesthesia following the paravertebral block was related to demyelination associated with MS.

\section{Clinical features}

The patient was a healthy 33-yr-old, white female who presented for a right inguinal hernia repair on the

From the Department of Anesthesiology and Pain Medicine, University of Alberta Hospital, Edmonton, Alberta, Canada. Address correspondence to: Dr. Brendan T. Finucane, Department of Anesthesiology and Pain Medicine, University of Alberta, Clinical Sciences Building, Room 8-120, Edmonton, Alberta T6G 2G3, Canada. Phone: 780-407-2876; Fax: 780-407-7461;

E-mail: bfinucan@ualberta.ca

Accepted for publication March 30, 2004.

Revision accepted Febuary 8, 2005. 
ambulatory surgery unit. Preoperative assessment revealed a healthy patient, weighing $60 \mathrm{~kg}$ and ASA physical status I. She had an allergic reaction to penicillin when she was a child. There was no other relevant history to report. She was reluctant to have the procedure performed under regional anesthesia but agreed to a paravertebral block for postoperative pain relief.

General anesthesia was induced using fentanyl 100 $\mu g$, propofol $150 \mathrm{mg}$ and lidocaine $2 \mathrm{mg} \cdot \mathrm{kg}^{-1} \mathrm{iv}$. A laryngeal mask airway was inserted and anesthesia was maintained with nitrous oxide, oxygen and desflurane. The surgery was uneventful. At the end of the procedure whilst still anesthetized, the patient was turned on her side and paravertebral blocks were performed at $\mathrm{T}_{12}$ to $\mathrm{L}_{1}$ and $\mathrm{L}_{1}$ to $\mathrm{L}_{2}$, using a 22-gauge Tuohy needle. The appropriate landmarks were identified with a marking pencil. The needle was inserted $2.5 \mathrm{~cm}$ from the midline on the right side at both levels. The needle was advanced until the transverse process was reached (at approximately $4 \mathrm{~cm}$ ). The needle was then withdrawn and redirected until it passed approximately $1 \mathrm{~cm}$ beyond the transverse process. Bupivacaine $0.5 \%, 6 \mathrm{~mL}$ was then injected at each level. There was no evidence of blood or cerebrospinal fluid coming from the needle, and there were no technical problems when performing the procedure. The patient was then transported to the recovery area at 08:20 and she quickly regained consciousness. She appeared to be pain free in recovery but was nauseated. One hour following her arrival in the recovery area (09:20) the patient was pain free but still nauseated, her blood pressure was $80 / 50 \mathrm{mmHg}$, and the nurse reported that her legs were flaccid. She had received a total of $8 \mathrm{mg} i v$ of ondansetron and was still nauseated. She received ephedrine $12.5 \mathrm{mg} i v$ and a bolus of $500 \mathrm{~mL}$ of normal saline. She had evidence of a block extending from $\mathrm{T}_{4}$ to the sacral roots bilaterally. The differential diagnosis entertained at that time was epidural, subarachnoid or subdural spread of local anesthetic from the paravertebral injection. The patient experienced no further episodes of nausea or vomiting and her vital signs remained stable. The patient was informed of our concerns and advised that she would have to remain in the day care unit until the block had fully regressed. She was discharged from the recovery area to the day care unit at 09:50. The patient's condition was again reviewed at 11:00. Her vital signs were stable but there was no sign of regression of the block. The patient did not report back pain or tenderness at the needle insertion site. At 15:30 the block had regressed to the inguinal region bilaterally and she was beginning to regain function in her legs. There was a concern about the possibility of urinary reten- tion, therefore a urinary catheter was inserted. The block completely regressed by 20:00 hr. The patient was discharged home at 21:00 hr that evening. A follow-up call was made the next day and the patient reported that she was pain free and did not have a headache. She had full recovery of all physiologic functions and there was no evidence of numbness or weakness in the lower extremities.

One month later the surgeon contacted us and informed us that the patient had communicated to him that she was diagnosed with MS shortly after she was discharged from hospital. We subsequently spoke to the patient who informed us that she had loss of sensation and numbness in the posterior thigh and calf region at the time of surgery before our intervention and that these signs had extended into her pelvic and trunk region one month prior to surgery. We contacted her neurologist who informed us that she had a magnetic resonance imaging evidence of lesions in the cervical spinal cord and corpus callosum one month following her surgery.

\section{Discussion}

This report generates two issues worthy of discussion. The first issue that we should attempt to address is what actually happened in this case? The differential diagnosis entertained at the time of the incident included: epidural, subdural, or subarachnoid spread and a remote possibility that this patient had an epidural hematoma. In view of the additional information subsequently provided by the patient, should we also consider an abnormal response to any of the above occurring in the presence of a demyelinating disease?

Epidural spread following paravertebral block is very common. Purcell-Jones et al., ${ }^{\mathrm{l}}$ using a contrast solution in combination with the local anesthetic, demonstrated epidural seepage in $70 \%$ of cases. Exclusive spread into the epidural space was observed in $31 \%$ of their cases. Spread was confined solely to the paravertebral space in only $18 \%$ of the 45 patients in that study. Even if $12 \mathrm{~mL}$ of $0.5 \%$ bupivacaine were injected directly into the epidural space one would not expect a 12-hr duration of the block. Furthermore, the degree and duration of motor blockade do not fit the clinical picture of an epidural anesthetic. Perhaps some or all of the local anesthetic entered the subarachnoid space (SAS). It is unlikely that both paravertebral injections entered the SAS because the patient would have presented with total spinal anesthesia. Judging by the proximity of the SAS to the paravertebral space (Figure) it is possible that some of the drug entered the SAS. ${ }^{2}$ It is also possible that the needle entered the SAS through a dural cuff. Postmortem 


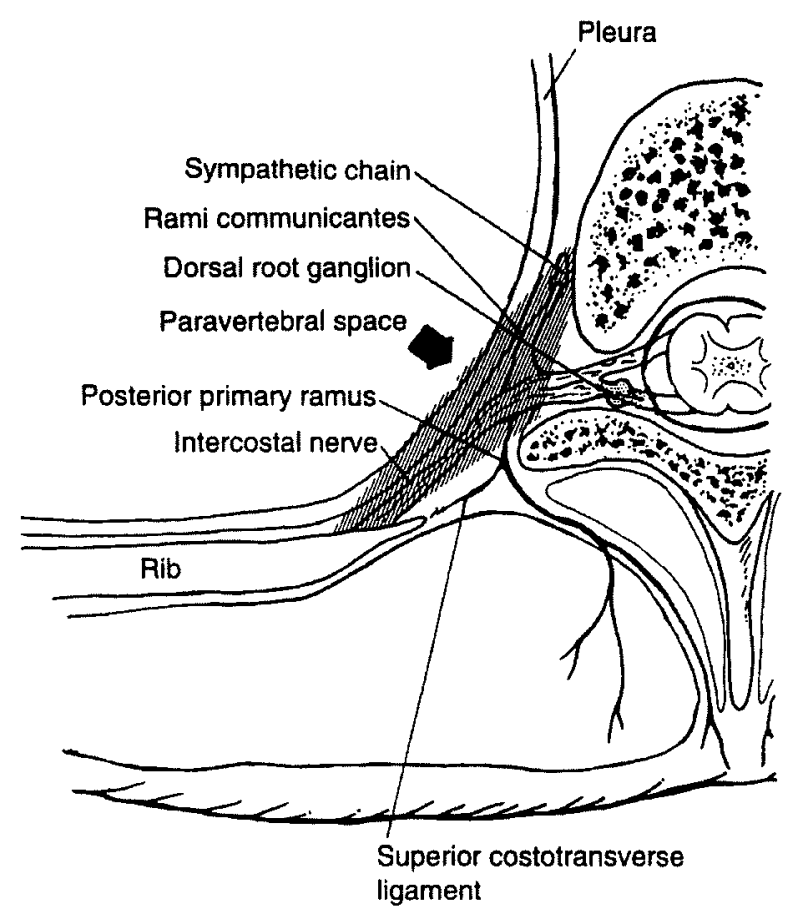

FIGURE The paravertebral space is defined by four borders: medially by the vertebral body; laterally by the intercostal space and costotransverse ligament; above by the bone and articular capsules of the rib and the transverse process; and below by the rib (modified with permission from Ferrante FM, Vade Boncouer TR. Postoperative Pain Management. New York: Churchill Livingstone; 1993).

studies have shown that the dural cuff can extend by as much as $8 \mathrm{~cm}$ beyond the intervertebral foramen. ${ }^{3}$ The characteristics of the block occurring in this patient more closely fit the description of a subarachnoid injection with the exception that the duration of action was far longer than one would expect. It is also possible to enter the subdural space from the dural cuff region close to the nerve root.

The incidence of subdural injection following epidural or subarachnoid injection has been reported to range between 0.1 to $0.8 \%{ }^{4}$ One would expect that to be even less following a paravertebral injection. Characteristics of a subdural injection of local anesthetics include a more rapid onset than epidural anesthesia and a slower onset than spinal anesthesia. Patients typically have an extensive proximal sensory block and a weak or absent motor block. "Spotty" and unilateral blocks are also characteristic of subdural blocks. ${ }^{5}$ We were unable to determine the rapidity of onset time because the patient was still recovering from the effects of general anesthesia. However, this patient did not present with any of the other typical signs of subdural block. Could this protracted block be in any way related to the presence of a demyelinating disease that was not yet diagnosed? The patient was being investigated for MS but she did not volunteer this information until several hours after the block was performed. When we subsequently received information that a diagnosis of MS was confirmed, the question was raised that perhaps her protracted response to the paravertebral blocks was related to the presence of a demyelinating disease.

A review of the literature on the implications of performing regional anesthesia in the presence of MS consists mostly of anecdotal case reports and very few trials, most of which are retrospective. Most of the studies and case reports involve obstetric patients. Both spinal and epidural anesthesia have been implicated as possible causes of reactivation of the disease. However there are conflicting reports supporting these allegations. Many of the factors that are linked with exacerbation of the disease, such as physical and emotional stress, fatigue, hyperthermia and infection ${ }^{6}$ also occur in the perioperative period. Lumbar punctures are frequently performed in patients with MS, ${ }^{7}$ yet there is no evidence that this diagnostic procedure is linked with exacerbation of the disease. Local anesthetics have been implicated as a possible cause of exacerbation of MS in patients undergoing central neural blockade. Bader et al. ${ }^{8}$ reported on a combined prospective/retrospective study of MS in obstetric patients receiving epidural anesthesia and local anesthesia infiltration for vaginal delivery at the Brigham and Women's Hospital between 1982 and 1987. They noted that all patients who experienced an exacerbation of MS had received epidural anesthesia with bupivacaine concentrations greater than $0.25 \%$.

Is it possible that there is a greater uptake of local anesthetics into the spinal cord following subarachnoid, epidural or paravertebral blocks in patients with MS? Concentrations of local anesthetics appearing in the white matter of the spinal cord are three to four times greater following spinal anesthesia than those following epidural anesthesia. ${ }^{9}$ Kytta et al. ${ }^{10}$ conducted a retrospective analysis of 56 patients with documented MS and noted that the five patients who received central neural blockade (three epidurals and two spinals) experienced extensive sympathetic blockade with marked hypotension and a reduced response to fluid and vasopressor therapy. They did not comment upon the duration of neural blockade. Therefore, there is some suggestion that local anes- 
thetics may have an exaggerated effect on the spinal cord in the presence of demyelination. Perhaps there is a greater uptake of local anesthetics into the spinal cord following spinal or epidural injections in the presence of demyelination. When one considers that local anesthetics spread from the paravertebral space into the epidural space in up to $70 \%$ of cases, there is some relevance to this case.

Within seven hours of the paravertebral injections the patient began to show signs of block regression. Therefore, concerns about an epidural hematoma were ruled out. If the patient had been awake when the block was performed, signs of subarachnoid or epidural spread would have been evident much sooner, and we would have been much less anxious about the possibility of a needle induced neurologic injury in this patient.

The second issue worthy of discussion is the concern about performing regional anesthesia in anesthetized patients. We certainly can be criticized for doing so in this case. However, there is no clear consensus on this issue world-wide. This practice is considered taboo in North Americall but not so in Europe. ${ }^{12}$ The pediatric example is frequently used in arguments. If it is considered safe to perform regional anesthesia in children who are anesthetized, why not in adults? The most cogent argument opposing the use of regional anesthesia in anesthetized patients is that most nerve injuries associated with regional anesthesia occur in patients who report paresthesia or pain on injection, ${ }^{13}$ and these valuable clinical signs cannot be obtained in anesthetized patients whether they are pediatric or adult. Do we concede that the comfort level for performing certain regional anesthesia procedures in anesthetized patients is greater? We frequently observe thoracic surgeons performing intercostal blocks on anesthetized patients without any obvious concern. Many anesthesiologists perform ankle blocks on anesthetized patients because they are painful to perform or because the patient agrees only if it is performed while they are anesthetized. Otherwise the patient is deprived of an excellent method of pain relief following foot surgery. On the other hand, few anesthesiologists are comfortable performing thoracic epidurals on anesthetized patients, and will not do so unless there is a very good reason. In this case, our comfort level for performing paravertebral blocks in an anesthetized patient was greater than that for many other blocks. The patient was interested in extended pain relief but only if she was anesthetized at the time of the nerve block. However, with the benefit of hindsight in this case we suggest that it is prudent to adhere to the tenet that, regional anesthesia should be per- formed in the awake state, especially when injecting local anesthetics into or close to the central neuraxis.

What did we learn from this case? We failed to elicit a history of neurologic disease from the patient during the preoperative assessment. If we had asked more probing questions about neurologic disease the patient probably would have volunteered information about upcoming investigations for MS. If we were aware that there was a possibility that the patient was in the early stages of MS we probably would have deferred the surgery. If surgery was not deferred, we probably would have avoided regional anesthesia.

In summary, a patient received a paravertebral block whilst under general anesthesia. She subsequently developed an extensive central neural blockade, which had many of the characteristics of a dense spinal anesthetic. However, the duration of the block was far longer than one would expect following a subarachnoid injection. During the course of regression of the block, the patient volunteered that she was being investigated for MS. It is our impression that the extended duration of central neural blockade following paravertebral block may have been related to an abnormal uptake of local anesthetic into the spinal cord in the presence of demyelination.

\section{References}

1 Purcell-Jones G, Pither CE, Justins DM. Paravertebral somatic nerve block: a clinical, radiographic, and computed tomographic study in chronic pain patients. Anesth Analg 1989; 68: 32-9.

2 Ferrante FM, VadeBoncouer TR. Postoperative Pain Management. New York: Churchill Livingstone; 1993.

3 Winnie AP. Plexus Anesthesia - Perivascular Techniques of Brachial Plexus Block. Philadelphia: WB Saunders Company; 1983: 243.

4 Lubenow T, Keh-Wong E, Kristof K, Ivankovich $O$, Ivankovich $A D$. Inadvertent subdural injection: a complication of an epidural block. Anesth Analg 1988; 67: 175-9.

5 Brown DL. Regional Anesthesia and Analgesia, lst ed. Philadelphia: WB Saunders; 1996: 454.

6 McDonald WI, Silberberg DH. Multiple Sclerosis. London: Butterworth; 1968.

7 Schapira K. Is lumbar puncture harmful in multiple sclerosis? J Neurol Neurosurg Psychiatr 1959; 22: 238.

8 Bader AM, Hunt CO, Datta S, Naulty JS, Ostheimer $G W$. Anesthesia for the obstetric patient with multiple sclerosis. J Clin Anesth 1988; 1: 21-4.

9 Stoelting RK, Dierdorf SF. Diseases of the nervous system. In: Stoelting RK, Dierdorf SF (Eds). Anesthesia and Co-existing Disease, 3rd ed. New York: Churchill Livingstone; 1993: 217. 
10 Kytta J, Rosenberg PH. Anaesthesia for patients with multiple sclerosis. Ann Chir Gynaecol 1984; 73 : 299-303.

11 Bromage PR, Benumoff JL. Paraplegia following intracord injection during attempted epidural anesthesia under general anesthesia. Reg Anesth Pain Med 1998; 23: 104-7.

12 Urmey WF, Fischer B. Regional anesthesia is potentially dangerous in anaesthetised adult patients - pro and con. In: Van Zundert A (Ed.). Highlights in Regional Anesthesia and Pain Therapy VIII. Cyprus:

Hadjigerorgiou; 1999: 291-300.

13 Auroy $\Upsilon$, Narchi P, Messiah A, Litt L, Rouvier B, Samii $K$. Serious complications related to regional anesthesia. Results of a prospective study in France.

Anesthesiology 1997; 87: 479-86. 